\title{
Acquired Methemoglobinemia- An Overview
}

\author{
Shibi Mary Thomas ${ }^{1, *}$, Jobin John Cherian², Syama Priya Thampi ${ }^{2}$, Blessy George ${ }^{3}$ \\ 1'Department of Pharmacy Practice, Faculty of Pharmacy, Karnataka College of Pharmacy, Bengaluru, Karnataka, INDIA. \\ ${ }^{2}$ Pharm D Intern, Bangalore Baptist Hospital, Bengaluru, Karnataka, INDIA. \\ ${ }^{3}$ Department of Pharmacy Practice, Chokkanahalli, Bengaluru, Karnataka, INDIA.
}

\begin{abstract}
Methemoglobinemia is a life-threatening condition that can be congenital or acquired. It is characterized by the inability of haemoglobin to carry oxygen because the ferrous part of the heme molecule has been oxidized to ferric state. Acquired methemoglobinemia is due to medication or chemicals that cause the rate of methemoglobin formation to exceed its rate of reduction. We performed a search of American National library of Medicine (PubMed) with the following key word "Acquired Methemoglobinemia". Two hundred forty-two episodes (40.1\% published in year 2000 or after) were found. A retrospective case series was found. In which it describes the cases of acquired methemoglobinemia detected and the clinical circumstances under which they occurred at two tertiary care hospitals and affiliated outpatient clinics over 28 months. One hundred thirty-eight cases of acquired methemoglobinemia were detected over 28 months. There were no gender predisposition and performed over a wide range of age (Patient aged 4 days to 86 years). Signs and symptoms of acquired methemoglobinemia usually occur within 20-30 min of drug administration. One of first sign is cyanosis. Early symptoms include anxiousness and dizziness, with fatigue and confusion. The diagnosis of methemoglobinemia is based on clinical assessment when respiratory status does not explain the cyanosis that a patient has and is refractory to oxygen therapy. As management of methemoglobinemia depends on precise detection, clinicians who administer or prescribe oxidizing agent must be aware of clinical symptoms of methemoglobinemia. Methylene blue is currently the drug of choice for the management of methemoglobinemia.
\end{abstract}

Key words: Methemoglobinemia, Haemoglobin, Ferrous, Ferric, Oxidation, Acquired Methemoglobinemia, Cyanosis, Anxiousness, Dizziness, Methylene Blue.

Synonyms

Haemoglobin M disease; Erythrocyte reductase deficiency; generalized reductase deficiency, Gibson's syndrome.

\section{INTRODUCTION}

Methemoglobin is the oxidized form of haemoglobin, which does not bind oxygen and increases the affinity of oxygen for the partially oxidized portion of haemoglobin. Increased levels of methemoglobin in the blood are secondary to congenital changes or exposure to several drugs, chemical agents, or food items resulting in a disorder with cyanosis. It can lead to death if not treated. ${ }^{1}$

\section{Normal Physiology}

The principle function of haemoglobin is to deliver oxygen from lungs to tissue cells, depending upon the variable affinity that haemoglobin has for oxygen. This affinity is principally dependent on the local partial pressure of oxygen $\left(\mathrm{pO}_{2}\right)$, but $\mathrm{pH}$, partial pressure of carbon dioxide $\left(\mathrm{pCO}_{2}\right)$, concentration of organic phosphates are also significant. Local conditions in the lungs (relatively high $\mathrm{pO}_{2}$, low $\mathrm{pCO}_{2}$, etc.) are associated with high affinity, so that haemoglobin readily binds oxygen here; the product of this binding is oxyhaemoglobin. By contrast in the microvasculature of the tissue, local condition (relatively low $\mathrm{pO}_{2}$, high $\mathrm{pCO}_{2}$, etc.) are associated with low haemoglobin affinity for oxygen and oxy haemoglobin readily dissociates, releasing oxygen to tissue cells.

\section{Haemoglobin and Methemoglobin}

The adult haemoglobin comprises four folded polypeptide chains (two alphas and two betas), each of which has a porphyrin heme group attached. ${ }^{2}$ At the centre of
DOI: 10.5530/ijopp.12.4.57

Address for correspondence: Prof. Shibi Mary Thomas, Assistant Professor, Faculty of Pharmacy, Department of Pharmacy Practice, Karnataka College of Pharmacy, Bengaluru, Karnataka, INDIA. Phone no: +919164600201 Email Id: shibipractice@gmail. com

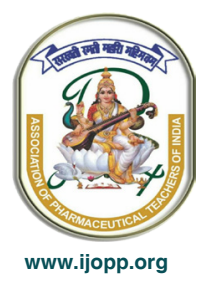


each of the four heme group is an atom of iron in the ferrous $\left(\mathrm{Fe}^{2+}\right)$ state. These four iron atoms are the functional centres of haemoglobin molecule because it is here that oxygen reversibly binds to form oxyhemoglobin. ${ }^{3}$ The only difference between haemoglobin and methemoglobin is that one or more of the four iron atoms in methemoglobin molecule are in ferric $\left(\mathrm{Fe}^{3+}\right)$ state rather than ferrous $\left(\mathrm{Fe}^{2+}\right)$ state and are therefore incapable of binding oxygen. ${ }^{4}$ Conversion of iron from the ferrous to ferric state represents loss of an electron, i.e. it is an oxidative process. ${ }^{5}$

When the haemoglobin, $\mathrm{Hgb}(\mathrm{Fe}(\mathrm{II})) \mathrm{O} 2$, is auto-oxidized to methemoglobin, $\mathrm{Hgb}(\mathrm{Fe}(\mathrm{III}))$, the methemoglobin, is recycled back to haemoglobin $\mathrm{Hgb}(\mathrm{Fe}(\mathrm{II}))$ so that in the steady state the amount of intracellular methemoglobin is $<1 \%$. The methemoglobin is reduced by the NADHcytochrome b5-metHgb reductase. In addition, reduction can be done by several alternative pathways such as NADPH-dependent MetHgb reductase and direct reduction by intracellular ascorbate and glutathione. ${ }^{6}$ (Figure 1)

\section{Epidemiology}

\section{United States}

Hereditary methemoglobinemia is a rare condition. This enzymatic deficiency is endemic in certain Native American tribes (Navajo and Athabascan Alaskans).

\section{International}

Methemoglobinemia occurs rarely throughout the world. Cytochrome b5 reductase deficiency (type Ib5R) is also endemic in the Yakutsk people of Siberia.

\section{Race}

The congenital form of methemoglobinemia due to cytochrome b5 reductase deficiency (type Ib5R) is endemic in certain ethnic groups. These groups include the Navajo, Athabascan Alaskans and the Yakutsk people in Siberia.

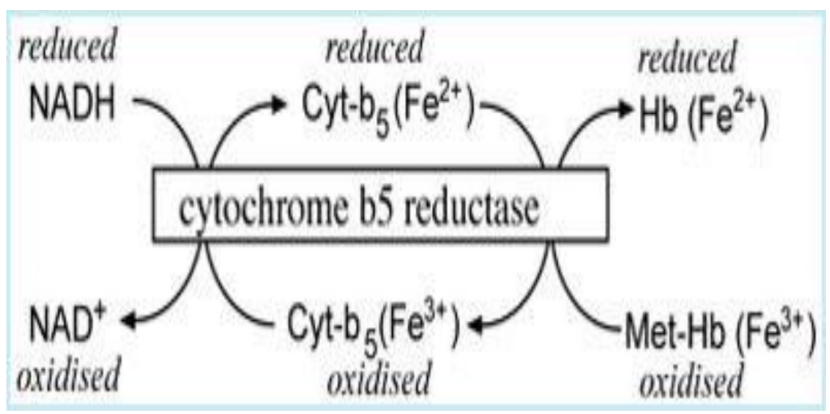

Figure 1: NADH dependent cytochrome b5 - methemoglobin reductase system.

Indian Journal of Pharmacy Practice, Vol 12, Issue 4, Oct-Dec, 2019
Sex

No difference exists in disease occurrence of acquired methemoglobinemia between males and females.

\section{Age}

Infants (especially premature infants) are more susceptible to the development of methemoglobinemia after drug or toxin exposure. This is because infants have significantly lower levels of cytochrome b5 reductase.

\section{Indian Perspective}

- In India, methemoglobinemia is not very common, which may be due to lack of awareness or lack of epidemiological studies on the disease.

- Groundwater is a major source of drinking water in rural Karnataka. Most districts, where drinking water is supplied through bore wells, have a high concentration of nitrates and fluorides. The main cause for these high concentrations is open sewage disposal and use of nitrogen fertilizers (D Majumdar-2003, the blue baby syndrome-Indian Academy of Sciences/Resonance, October 2003. pp. 20-30).

- The sanitation coverage in some districts like Gulbarga, Bijapur, Raichur and Tumkur is below 20\%.

- Fertilizer consumption in India is concentrated in about one-third of the cultivated area.

- In India, the chemical industry is growing rapidly in the western part, mainly in Gujarat and Maharashtra. Ahmedabad is surrounded by a large number of industrial units manufacturing dyes and dye intermediates. Workers in these units are at high-risk of developing acute methemoglobinemia. ${ }^{7}$

- An analysis of nitrates in the groundwater in Punjab by Greenpeace revealed nitrate pollution in drinking water. The most significant potential health effects of drinking water contaminated with nitrate are the blue-baby syndrome, methemoglobinemia and cancer.

- A study from three districts of West Bengal highlights occupational morbidity among agricultural child labour. Apart from deaths due to explosions and fire, coughing, sore throat, dizziness, methemoglobinemia and anemia are common effects of ingestion or inhalation of chlorate dust. ${ }^{8}$

- Congenital methemoglobinemia due to NADH-methemoglobin reductase deficiency in three Indian families recognized in a Mumbai-based study.

\section{Clinical Features and Pathophysiology}

Symptoms are proportional to the fraction of methemoglobin. A normal methemoglobin fraction is about $1 \%$ (range, $0-3 \%$ ). 
At methemoglobin levels of 3-15\%, a slight discoloration (eg, pale, grey, blue) of the skin may be present.

Patients with methemoglobin levels of 15-20\% may be relatively asymptomatic, apart from mild cyanosis. Signs and symptoms at levels of $25-50 \%$ include the following:

- Headache

- Dyspnea

- Light-headedness, even syncope

- Weakness

- Confusion

- Palpitations, chest pain

Methemoglobin levels of $50-70 \%$ can cause the following:

- Cardiovascular - Abnormal cardiac rhythms

- CNS - Altered mental status; delirium, seizures, coma

- Metabolic - Profound acidosis

In normal persons, the methemoglobin (met Hgb) levels are kept below $1 \%$ by an nicotinamide adenine dinucleotide phosphate (NADPH) dependent methemoglobin reductase enzyme which is effective in reducing methemoglobin back to the ferrous state, (NADPH) pathway, a second enzymatic system which reduces methemoglobin to haemoglobin, is directly dependent on both the activity of glutathione and glucose-6-phosphate dehydrogenase). However hereditary deficiencies in the activity of this enzyme result in chronic methemoglobin levels of $40 \%$ to $50 \%$. Methemoglobin is formed by oxidation of the ferrous iron $(\mathrm{Fe}(2+))$ of haemoglobin to ferric $(\mathrm{Fe}(3+))$ form by oxidizing chemical or drugs this reaction impairs the ability of haemoglobin to transport oxygen and carbon dioxide, leading to tissue hypoxemia and in severe cases, death. ${ }^{10}$

\section{Aetiology}

Congenital (hereditary) methemoglobinemia

Hereditary methemoglobinemia may be divided into two categories as follows: ${ }^{5}$

- Methemoglobinemia due to an altered form of haemoglobin (i.e., $\mathrm{Hb} \mathrm{M}$ )

- Methemoglobinemia due to an enzyme deficiency (NADH reductase deficiency) that decreases the rate of reduction of iron in the haemoglobin molecule

Several variants of haemoglobin $\mathrm{M}$ have been described, including $\mathrm{Hb} \mathrm{Ms}, \mathrm{Hb}_{\text {Iwate }}, \mathrm{Hb} \mathrm{M}_{\text {Boston, }}, \mathrm{Hb} \mathrm{M}_{\text {Hyde Park }}$ and $\mathrm{Hb} \mathrm{M} \mathrm{S}_{\text {Saskatoon }}$. These are usually autosomal dominant in nature. Alpha-chain substitutions cause cyanosis at birth, whereas the effects of beta-chain substitutions become clinically apparent in infants at 4-6 months of age.

There are four types of hereditary methemoglobinemia that are secondary to deficiency of NADH cytochrome b5 reductase, which is encoded by the CYB5R3gene. All of them are autosomal recessive disorders. Heterozygotes have $50 \%$ enzyme activity and no cyanosis; homozygotes that have elevated methemoglobin levels above $1.5 \%$ have clinical cyanosis. The four types are as follows:

- Type I - This is the most common variant and the enzyme deficiency is limited to the erythrocytes causing cyanosis; cyanosis usually, but not always, develops during infancy. ${ }^{11}$

- Type II - Widespread deficiency of the enzyme occurs in various tissues, including erythrocytes, liver, fibroblasts and brain; it is associated with severe CNS symptoms, including encephalopathy, microcephaly, hypertonia, athetosis, opisthotonos, strabismus, mental retardation and growth retardation; cyanosis is evident at an early age.

- Type III - Although the hematopoietic system (platelets, RBCs and white blood cells [WBCs]) is involved, the only clinical consequence is cyanosis.

- Type IV - Like type I, this type has isolated involvement of the erythrocytes but results in chronic cyanosis.

Deficiency of NADPH-flavin reductase can also cause methemoglobinemia.

\section{Acquried Methmolobinemia}

The $\mathrm{Hgb}(\mathrm{Fe}(\mathrm{II})) \mathrm{O}_{2}$ methemoglobin $\mathrm{Hgb}(\mathrm{Fe}(\mathrm{III}))$ couple can undertake redox transformations under a number of important biological situations and it is no surprise that xenobiotic are substrates, forming methemoglobin in the process. The acquired formation of methemoglobin can have consequences. While $\mathrm{Hgb}(\mathrm{Fe}(\mathrm{II}))$ can be oxidized directly by some xenobiotic to form methemoglobin, resulting in the reduction of the xenobiotic, the usual reaction is the oxidation of the xenobiotic by $\mathrm{Hgb}(\mathrm{Fe}(\mathrm{II}))$ $\mathrm{O}_{2}$, resulting in $\mathrm{H}_{2} \mathrm{O}$ and methemoglobin. ${ }^{6}$

There are two basic mechanisms for acquired methemoglobinemia: direct or indirect oxidation of the haemoglobin. Rarely the $\mathrm{Fe}(\mathrm{II})$ in haemoglobin, $\mathrm{Hgb}(\mathrm{Fe}(\mathrm{II})$ ), can be directly oxidized to $\mathrm{Fe}(\mathrm{III})$ to form methemoglobin. Direct oxidation can be caused by chlorates, hexavalent chromates, cobalt and copper II salts. $^{12}$

Indirect oxidation is more prevalent. Oxidation occurs with participation of both the iron and the oxygen, with superoxide and hydrogen peroxide production when the haemoglobin bound oxygen accepts electrons from ferrous iron. ${ }^{13}$ Aniline is a potent inducer of methemoglobinemia and haemolysis, but is converted first to phenylhydroxylamine that is oxidized to 
nitrosobenzyene by $\mathrm{Hgb}(\mathrm{Fe}(\mathrm{II}))$ and oxygen. Figure 2

The nitrosobenzene is subsequently reduced by a NADPH flavin reductase back to aniline, using NADPH derived from glucose-6-phoshate dehydrogenase and the hexose monophosphate shunt. ${ }^{14}$ Alternatively, glutathione can be used as a source of reducing power. ${ }^{15,16}$ Aniline and nitros-derivatives are transformed into phenylhydroxylamines by hepatic mixed function oxidases and then can become inducers of methemoglobin. ${ }^{17}$ Such bioactivation is important for the toxic effects of dapsone and sulfamethoxazole (the sulfa component in trimethoprim-sulfamethoxazole, Septra, or Bactrim), probably via the formation of hydroxylamines. The dapsone hydroxylamine was the more potent in forming methemoglobin and consuming glutathione compared to the sulfamethoxazole hydroxyl amine, paralleling the in vivo findings. ${ }^{18}$

\section{Evaluation}

Investigations to rule out haemolysis (Complete Blood Count $[\mathrm{CBC}]$, reticulocyte count, peripheral smear review, Lactate Dehydrogenase [LDH], bilirubin, haptoglobin and Heinz body preparation) and end-organ dysfunction or failure (liver function tests, electrolytes, renal function tests) should be included in the workup. Urine pregnancy tests should be performed in females of childbearing age.

Investigations to evaluate a hereditary cause for methemoglobinemia should be ordered when appropriate. Haemoglobin electrophoresis and DNA sequencing of the globin chain gene can be used to identify haemoglobin M.

Specific enzyme assays (Nicotinamide Adenine Dinucleotide [NADH]-dependent reductase, cytochrome b5 reductase) may be determined, often in multiple cell lines (i.e., platelets, granulocytes and fibroblasts), to diagnose inherited cases. A quick and easy bedside

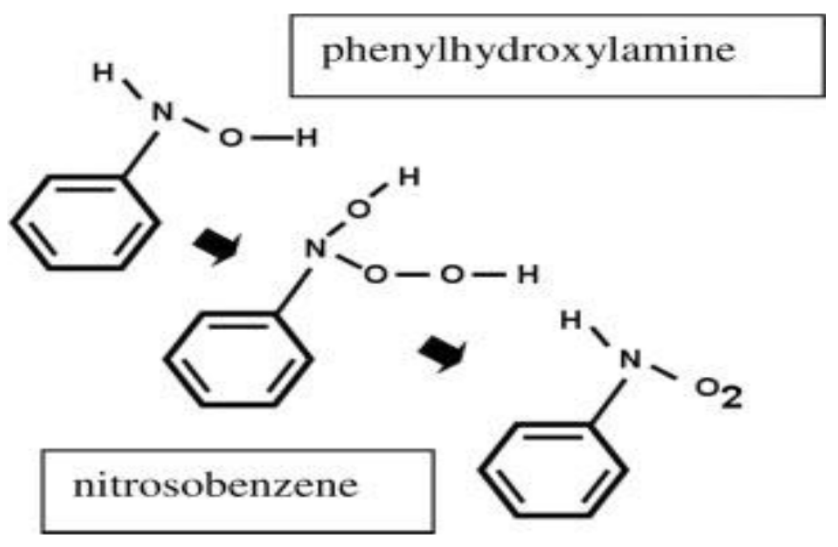

Figure 2: Oxidation of the aniline derivative catalysed by oxygenated haemoglobin.
Drugs that induce Methemoglobinemia.

\begin{tabular}{|c|c|}
\hline Medical Group & Drugs \\
\hline $\begin{array}{l}\text { Analgesic and } \\
\text { Antipyretics }\end{array}$ & $\begin{array}{c}\text { Acetaminophen-Phenacetin-Antipyrin } \\
\text { (Antipyrin and Benzocain Auralgan } ®) \\
\text { Opiate Agonists: Fentanyl Urinary Tract } \\
\text { Analgesic: } \\
\text { Phenazopyridine Celecoxib }\end{array}$ \\
\hline Anticonvulsants & $\begin{array}{l}\text { Phenobarbital, Phenytoin, Sodium } \\
\text { Valproate }\end{array}$ \\
\hline Antimicrobials & $\begin{array}{c}\text { Sulfonamide: Cotrimcxazole } \\
\text { (Sulfamethoxazole-Trimethoprim)- } \\
\text { Sulfanilamide-Sulfapyridine-Sulfathiazole } \\
\text { Solfon: Dapsone Nitrofurantoin } \\
\text { Clofazimine } \\
\text { Phenazopyridine hydrochloride }\end{array}$ \\
\hline Antimalarial & $\begin{array}{l}\text { Chloroquine-Primaquine Phosphate- } \\
\text { Quinine }\end{array}$ \\
\hline Antituberculosis & Para-Aminosalicylic Acid-Rifampin \\
\hline Hormones & Flutamide \\
\hline Psychotherapeutic & Phenelzine; Piperazine; Trazodone \\
\hline Nitrate derivative & $\begin{array}{l}\text { Nitroglycerin; Isosorbide Dinitrate; Silver } \\
\text { Nitrate; Sodium Nitrate; Nitrate Salt; } \\
\text { Erythrityl Tetranitrate }\end{array}$ \\
\hline Nitrits Derivative & $\begin{array}{l}\text { Amyl Nitrite; Bismuth Subnitrite; Sodium } \\
\text { Nitroprusside; Sodium Nitrite; Nitric Oxide }\end{array}$ \\
\hline $\begin{array}{c}\text { Topical } \\
\text { Anaesthetic }\end{array}$ & $\begin{array}{l}\text { Benzocaine; Lidocaine hydrochloride; } \\
\text { Prilocaine hydrochloride }\end{array}$ \\
\hline Local Anaesthetics & $\begin{array}{c}\text { Amethocain; Articaine; Benzocain; } \\
\text { Cetacaine; Lidocaine; Prilocaine; } \\
\text { Procaine; Bupivacaine Hydrochloride }\end{array}$ \\
\hline Other Topical & Hydroquinone; Potassium Permanganate \\
\hline $\begin{array}{l}\text { Anti-Infective } \\
\text { Topical }\end{array}$ & $\begin{array}{c}\text { Carbol-Fuchsin Topical Solution (Phenol; } \\
\text { Resorcinol; Basic Fuchsin (Rosanilind And } \\
\text { Pararosaniline Hydrochlorides) Cetrimide; } \\
\text { Triclocarbon } \\
\text { Soap (TCC) }\end{array}$ \\
\hline Other & $\begin{array}{l}\text { Methylene Blue; Metoclopramide } \\
\text { Hydrochloride; Riluzole; Rasburicase }\end{array}$ \\
\hline
\end{tabular}

test for determining whether dark blood is due to methemoglobinemia is to bubble $100 \%$ oxygen in a tube that contains the dark blood. Blood that remains dark likely does so because of the presence of methemoglobin.

Another simple test (and one that is less likely to splash potentially infectious blood) is to place 1-2 drops of blood on white filter paper, then evaluate for colour change upon exposure to oxygen. (This test can be accelerated by gently blowing supplemental oxygen onto the filter paper.) Deoxygenated haemoglobin changes from dark red or violet to bright red, whereas methemoglobin remains brown.

Serum levels of nitrites or other offending drugs may be determined. Often, these results are not immediately available and treatment may have to be started empirically if the index of suspicion is high. 


\section{Arterial Blood Gas Determination}

The presence of methemoglobin can falsely elevate the calculated oxygen saturation when Arterial Blood Gases (ABGs) are obtained. One possible clue to the diagnosis of methemoglobinemia is the presence of a "saturation gap." This occurs when there is a difference between the oxygen saturation measured on pulse oximetry and the oxygen saturation calculated on the basis of $A B G$ results.

The partial Pressure of Oxygen $\left(\mathrm{PO}_{2}\right)$ value of the ABG measurement reflects plasma oxygen content and does not correspond to the oxygen-carrying capacity of haemoglobin. It should be within the reference range in patients with methemoglobinemia.

\section{Oximetry}

\section{Co-oximetry}

Co-oximetry should be performed if available. The co-oximeter is an accurate device for measuring methemoglobin and is the key to diagnosing methemoglobinemia. It is a simplified spectrophotometer that can measure the relative absorbance of 4 different wavelengths of light and thus is capable of differentiating methemoglobin from carboxyhemoglobin, oxyhemoglobin and deoxyhemoglobin. Newer co-oximeter can also measure sulfhemoglobin, which can be confused with methemoglobin by older devices.

Availability of appropriate equipment may be a problem. Lipemic specimens may result in a falsely elevated methemoglobin level. In addition, the presence of methylene blue interferes with the accurate measurement of methemoglobin by co-oximetry, hence this method cannot be used to monitor methemoglobin levels after treatment with methylene blue is initiated. Blood substitutes can cause co-oximetry to yield unreliable results.

\section{Pulse oximetry}

Pulse oximetry is used extensively in the evaluation of patients with cyanosis and respiratory distress. Findings of bedside pulse oximetry in the presence of methemoglobinemia may be misleading. Pulse oximetry measurements with low-levels of methemoglobinemia often result in falsely low values for oxygen saturation and are often falsely high in those with high-level methemoglobinemia. The reason for these inaccuracies is as follows.

The pulse oximeter only measures the relative absorbance of 2 wavelengths of light $(660 \mathrm{~nm}$ and $940 \mathrm{~nm})$ to differentiate oxyhemoglobin from deoxyhemoglobin. The ratio of absorption of light at each of these wavelengths is converted into oxygen saturation by using calibration curves. Methemoglobin increases absorption of light at both wavelengths (more at $940 \mathrm{~nm}$ ) and therefore offers optical interference to pulse oximetry by falsely absorbing light.

As a result, oxygen saturations by pulse oximetry in methemoglobinemia plateau at about $85 \%$; therefore, a patient with a methemoglobin level of $5 \%$ and a patient with a level of $40 \%$ have approximately the same saturation values on pulse oximetry $(\sim 85 \%)$. The severity of the cyanosis does not correspond to the pulse oximetry reading: A patient may appear extremely cyanotic but still have a pulse oximetry reading in the high $80 \mathrm{~s}$.

\section{Treatment}

Early clinical recognition of methemoglobinemia is paramount, as patients often have only vague, nonspecific complaints, especially in the initial phase. High levels of methemoglobinemia can be life-threatening and necessitate emergency therapy. Treatment is advisable for patients with acute exposure to an oxidizing agent who have methemoglobin levels of $20 \%$ or higher. Patients with significant comorbidities (eg, Coronary Artery Disease [CAD] or anaemia) may require therapeutic intervention at lower methemoglobin levels (eg, 10\%), especially if end-organ dysfunction (eg, cardiac ischemia) is present. If methemoglobinemia is the result of toxin exposure, then removal of this toxin is imperative. Further ingestion or administration of the drug or chemical should be avoided.

\section{Pharmacologic Therapy, Exchange Transfusion and Hyperbaric Oxygen}

Methylene blue is the primary emergency treatment for documented symptomatic methemoglobinemia. It is given in a dose of $1-2 \mathrm{mg} / \mathrm{kg}$ (up to a total of $50 \mathrm{mg}$ in adults, adolescents and older children) as a $1 \%$ solution in IV saline over 3-5 min. Administration may be repeated at $1 \mathrm{mg} / \mathrm{kg}$ every $30 \mathrm{~min}$ as necessary to control symptoms. Methylene blue is itself an oxidant at doses greater than $7 \mathrm{mg} / \mathrm{kg}$ and thus may cause methemoglobinemia in susceptible patients; hence, careful administration is essential.

Methylene blue is contraindicated in patients with G6PD deficiency. Because it requires G6PD to work, it is ineffective in G6PD-deficient patients with methemoglobinemia. Additionally, methylene blue administration may cause haemolysis in these patients.

Methylene blue is also not effective in patients with haemoglobin $\mathrm{M}(\mathrm{HbM})$. Other conditions in which methylene blue may be ineffective or even deleterious 
include Nicotinamide Adenine Dinucleotide Phosphate (NADPH) methemoglobin reductase (i.e., diaphorase II) deficiency and sulfhemoglobinemia.

Exchange transfusion (which replaces abnormal haemoglobin with normal haemoglobin) may be considered for G6PD-deficient patients who are severely symptomatic or unresponsive to methylene blue. Patients who are on long-acting medication (eg, dapsone) may have initial treatment success with subsequent relapse of symptoms. Gastric lavage followed by charcoal administration may decrease this prolonged drug effect. These patients should be monitored closely and retreated with methylene blue as necessary.

Hyperbaric oxygen treatment is another option for situations where methylene blue therapy is ineffective or contraindicated. This approach permits tissue oxygenation to occur through oxygen dissolved in plasma, rather than through haemoglobin-bound oxygen.

Infants with methemoglobinemia due to metabolic acidosis should be treated with IV hydration and bicarbonate to reverse the acidosis. The NADPHdependent methemoglobin reductase enzyme system requires glucose for the clearance of methemoglobin. Therefore, IV hydration with Dextrose 5\% in Water (D5W) is often effective.

Patients with mild chronic methemoglobinemia due to enzyme deficiencies may be treated with oral medications in an attempt to decrease cyanosis. These medications include methylene blue, ascorbic acid and riboflavin. The methylene blue dosage in this setting is $100-300 \mathrm{mg} /$ day, which may turn the urine blue in colour. The ascorbic acid dosage is $200-500 \mathrm{mg} /$ day; unfortunately, long-term oral ascorbic acid therapy can cause the formation of sodium oxalate stones. The riboflavin dosage is $20 \mathrm{mg} /$ day.

Cimetidine can be used in dapsone-induced methemoglobinemia to prevent further formation of its metabolite. $N$-acetyl cysteine has been shown to reduce methemoglobin in some studies but is not currently an approved treatment for methemoglobinemia.

No pharmacologic treatment exists for hereditary forms of methemoglobinemia.

\section{CASE REPORTS}

Case 1: A 16 year old boy was admitted in emergency department, after he had collapsed after a dental extraction in which Prilocaine hydrochloride 3\% was used as topical anaesthesia. The patient is deeply cyanosed despite a good respiratory effort, a clear airway and bilateral breath sounds. Oxygen saturation is $60 \%$ with patient breathing in room air. Assisted ventilation started, cyanosis didn't improved. The attending consultant is alert for the possibility of methemoglobinemia. A blood specimen is drawn and the test results confirm the diagnosis of methehemoglobinemia. ${ }^{19}$

Case 2: A boy aged 18 months came to paediatric emergency, suspected as unknown poisoning. He has a history of vomiting, excessive irritability and seizure. After examination, it was found child has severe cyanosis, oxyhemoglobin saturation $\left(\mathrm{SpO}_{2}\right)$ to be only $86 \%$.

His blood was chocolate brown in colour. His $\mathrm{PaO}_{2}$ was $265 \mathrm{mmHg}$. In view of high $\mathrm{PaO}_{2}$ and low $\mathrm{SpO}_{2}$, methemoglobinemia was suspected. Arterial blood gas analysis with co-oximetry showed methemoglobin to be $39 \%$. This confirmed methemoglobinemia. ${ }^{20}$

Case 3: A 39 year old woman who had a small bowel obstruction after resection of an appendical carcinoid tumour was given benzocaine topical spray for retropharyngeal discomfort. Within few minutes, she became ashen, dyspnoea and tachypeanic with an oxygen saturation of $73 \%$. In the arterial blood gas values: Partial pressure of oxygen $507 \mathrm{mmHg}$, methemoglobin level $48.2 \%$ and oxyhemoglobin level $51.3 \%$ was found. This lead to the diagnosis of acquired methemoglobinemia. ${ }^{21}$

Case 4: A 69-year-old white female patient weighing 175lb came for a transesophageal echocardiogram to assist in the evaluation of intracardiac thrombus. The patient had a history of ischemic heart disease, post coronary artery bypass, hypertension, post-menopausal hyperlipidaemia, type 2 diabetes mellitus, obesity and symptomatic atrial fibrillation. The patient was apparently taking the following medication: Amiodarone, aspirin, enoxaparin, glyburide, levothyroxine, metoprolol succinate, niacin, rabeprazole sodium and simvastatin and warfarin sodium. During transesophageal echocardiogram, the patient oxygen saturation level was measured at $90 \%$ by room air pulse oximetry so the oxygen level was adjusted. Results from the procedure were with in normal limits, so the cardio version was completed and was successful and benzocaine spray was applied orally. After 15 min post procedure, patient developed central cyanosis and oxygen saturation level suddenly decreased to $70 \%$. Methemoglobinemia was suspected and then confirmed by arterial blood gasses obtained, where $\mathrm{PaO}_{2}$ was 293 and methemoglobin was $41.1 \% .^{22}$

Case 5: A 52-year-old man with squamous cell cancer of the retro molar trigone region was scheduled for a radical neck dissection and partial mandibuloctomy. Because of concern to intubate this patient, a topical $2 \%$ viscous Lidocaine $5 \mathrm{ml}$, followed by two $1 \mathrm{sec}$ spray of Cetacaine 
(14\% benzocaine, $2 \%$ tetracaine and other ingredient). Laryngoscopy correctly predicted an easy intubation and thus induced anaesthesia in a routine intravenous manner. Over the next hour the pulse oximeter displayed a progressive in oxygen saturation from $99 \%$ to $94 \%$ and eventually to mid-80s after 3 hrs. Arterial blood gas revealed 26\% methemoglobin. And patient is diagnosed with methemoglobinemia. ${ }^{23}$

\section{CONCLUSION}

Methemoglobin is a useless form of haemoglobin, which is constantly being formed in red blood cells of peripheral blood. However, due to the effect of enzyme reducing system that converts methemoglobin to haemoglobin, concentration remains low in health. Increased level of methemoglobin, termed methemoglobinemia, reducing oxygenation of tissue cells, causing cyanosis. Severe methemoglobinemia (methemoglobin $>70 \%$ of total haemoglobin) is potentially fatal. A drug rarely produce methemoglobinemia when given in recommended dose to normal persons but acquire methemoglobinemia appears to be relatively common in infants within three months and patients with congenital deficiencies following exposed to oxidants drugs. Monitoring of methemoglobin levels suggested in patient with high risk of methemoglobinemia.

\section{ACKNOWLEDGEMENT}

Department of Pharmacy Pratice, Karnataka College of Pharmacy for providing necessary guidance.

\section{CONFLICT OF INTEREST}

Shibi Mary Thomas and Jobin John Cherian have no conflict of interest that are directly relevant to the content of this case study.

\section{REFERENCES}

1. Ramanamurty SV. Methemoglobinemia: A Reappraisal with an Indian Perspective. Haematology. 2013.

2. Ranney HM, Sharma V. Structure and Function of Hemoglobin. William's Hematology (6 th edition) McGraw Hill. 2000;345-53.
3. Wittenburg J, Wittenberg B, Peisach $\mathrm{J}$, et al. On the state of the iron and the nature of the ligand in oxyhemoglobin. Proc Natl Acad Sci. 1970;67(4):1846-53.

4. Price D. Methemoglobinemia. In: Goldfrank's toxicological emergencies ( $7^{\text {th }}$ edition) New York: McGraw Hill. 2002;1438-39.

5. Wright R, Lewader W, Woolf A. Methemoglobinemia: Etiology, pharmacology and clinical management. Ann Emerg Med. 1999;34(5):646-56

6. Jay U. Methemoglobin-It's Not Just Blue: A Concise Review. American Journal of Hematology. 2007;82(2):134-44.

7. Aruna $\mathrm{D}$, et al. Acute Methemoglobinemia- A common occupational hazard in an industrial city in western India. J Occup Health. 2001;43(3):168-71.

8. Sekhar HR. Children at health risks. ICCW New Bulletin. 1992;40(3-4):53-9.

9. Kedar PS, Cloah RB, Ghosh K, et al. Congenital methemoglobinemia due to NADH-methemoglobin reductase deficiency in three Indian families. Hemoglobia Budap. 2002:32(4):543-9.

10. Menyfah QA. Drugs may be Induced Methemoglobinemia. Journal of Hematology and Thromboembolic Diseases. 2017;5(3):1-5.

11. Forestier A, Pissard S, Cretet J, Mambie A, Pascal L, Cliquennois M, et al. Congenital Recessive Methemoglobinemia Revealed in Adulthood: Description of a New Mutation in Cytochrome b5 Reductase Gene. Hemoglobin. 2015;39(6):1-4

12. Horiguchi H, Oguma E, Nomoto S, Arao Y, Ikeda K, Kayama F. Acute exposure to cobalt induces transient methemoglobinuris in rats. Toxicol Lett. 2004;151(3):459-66.

13. Titov VY, Petrenko YM. Proposed mechanism of nitrite induced methemoglobinemia. Biochemistry. 2005;70(4):473-83.

14. Kiese $M$. The biochemical production of ferrihemoglobin-froming derivatives from aromatic amines and mechanisms of ferrihemoglobin formation. Pharmacol Rev. 1966;18(3):1091-161.

15. Coleman MD, Simpson J, Jacobus DP. Reduction of dapsone hydroxylamine to dapsone during methaemoglobin formation in human erythrocytes in vitro. IV: Implications for the development of agranulocytosis. Biochem Pharmacol. 1994;48(7):1349-54

16. Kramer PA, Glader BE, Li T-K. Mechanism of methemoglobin formation by diphenylsulfone: Effect of 4-amino-40-hydroxyaminodiphenylsulfone and other p-substituted derivatives. Biochem Pharmaol. 1972;21:1265-74.

17. Singh H, Purnell ET. Aniline derivative-induced methemoglobin in rats. J Environ Pathol Toxicol Oncol. 2005;24(1):57-65.

18. Reilly TP, Woster PM, Svensson GK. Methemoglobin formation by hydrosylamine metabolites of sulfamethoxazole and dapsone: Implications for differences in adverse drug reactions. J Pharmacol Exp Ther. 1999;288(3):951-9.

19. Habib UR. Specialist registrar. Methemoglobinemia. West J Med. 2001;175(3):193-6.

20. Sibabratta P, Manivachagan MN, Ebor JJ, Kala E. Methylene blue unresponsive methemoglobinemia. Indian J Crit Care Med. 2014;18(4):253-5.

21. Gerard B, Donnelly MD, Diana RMS. Methemoglobinemia. N Engl J Med. 2000;343(5):337

22. Sandra KB. Benzocaine-Induced Methemoglobinemia during Transesophageal Echocardiography. The Journal of the American Osteopathic Association. 2005;105(8):381-4

23. Anderson ST, Hajduczek J, Barker SJ. Benzocaine-induced methemoglobinemia in an adult: accuracy of pulse oximetry with methemoglobinemia. Anesth Analg 1988;67(11):1099-101.

Kristina EW, Michelle WMC. Dapsone-Induced Methemoglobinemia. Annals of Pharmacotherapy. 1998;32(5):549-53. 